\title{
Future sea level rise implications on development of Lazarus Island, Singapore Southern Islands
}

\author{
T. S. Teh, D. K. Raju, K. Santosh \& J. Chandrasekar \\ Tropical Marine Science Institute, National University of Singapore, \\ Singapore
}

\begin{abstract}
The Southern Islands compose an urban planning area in the Central Region of Singapore and is made up of the islands of Kusu, Lazarus, Seringat, Tekukor, St. John, Sentosa and the Sister Islands. The islands had largely been expanded by land reclamation in the 1970s to create beaches and swimming lagoons. The new coastlines are armoured by large quarry stones. Other than Sentosa, the rest of the islands are undeveloped and remain as mainly weekend destinations.

As part of the Singapore Tourism Board's plan to develop the Southern Islands beyond Sentosa, a second phase of land reclamation with sands imported from Indonesia was started in 2000 to link Seringat, Lazarus and Sentosa. The land reclamation took six years to complete and water, electricity, gas and telecommunication infrastructure were brought to the island from Sentosa. The entire project costs nearly $\mathrm{S} \$ 300$ million.

The strengths and opportunities identified are the unspoilt natural environment, island ambience free from vehicular traffic and proximity to the mainland's central area. The ' waters of the southern islands have attractive corals and marine life and are popular diving spots. Beaches are of reasonable quality and topographic highs on some islands offer trekking possibilities. The main constraints to developing the islands are absence of road and poor navigational access to the islands. Over the years, there have been various suggestions on how Lazarus Island should be developed. Recent suggestions include turning the island into a getaway for the super rich or housing a casino.

However, whatever development is planned for Lazarus must take into consideration its sustainability in the face of a future rising sea. Reclamation that took place in the 1970s was before concern about global warming. Consequently,
\end{abstract}


the crest of sea walls and platform levels of reclaimed land are low and vulnerable to wave overtopping and inundation during extreme high tides. Inundation analyses using Geographic Information System carried out under A2 sea level rise scenario for Lazarus suggest that extra care must be taken in developing these islands to avoid future problems.

Keywords: Lazarus Island, island development, land reclamation, vulnerability, sea level rise, A2 emission scenario, RTK, DEM, GIS, inundation.

\section{Introduction}

Planning without considering a possible rising sea may render some of the best conceived land use plan to fail. Global warming and a rising sea is a recent concern and the early plans did not have to address this issue. However, newer plans for coastal areas and islands are expected to accommodate a rising sea. Unfortunately, there is much uncertainty regarding the quantum of rise and there are questions whether designs of coastal structures and platform levels of reclaimed land are adequate to protect existing coastal settlements, and whether any proposed plan to encourage settlement along the coast and on islands is wise.

\section{Objectives}

This paper examines the sustainability of proposed plans to develop Lazarus Island under the threat of a rising sea. A2 emission scenario for various time frames are examined, areas vulnerable to inundation identified using GIS analyses and recommendations made to mitigate or avoid future problems ensuing from a rising sea.

\section{Planning system in Singapore}

Careful planning is carried out in Singapore in order to achieve sustainable economic growth and ensure a high quality of life. This is done through the Concept Plan and Master Plan, which provide a comprehensive forward looking and integrated planning framework for sustainable development [1]. The Master Plan which was first formulated during 1952-1955 and approved in 1958 has since undergone eight reviews.

The Concept Plan, reviewed every 10 years, is a strategic land use and transportation plan to guide development in the next $40-50$ years. This integrated plan attempts to provide sufficient land to meet anticipated population and economic growth and to provide a good living environment. It takes into account all major current land use needs, balances future needs and considers all tradeoffs, thus ensuring economic growth with environmental stewardship and social progress.

The Master Plan, reviewed every 5 years, is a statutory land use plan which guides Singapore's development in the medium term over the next 10-15 years. The plan, one of the most important tools in shaping Singapore's physical 
development, translates the Concept Plan into detailed plans. In the Master Plan, Singapore is divided into five planning regions, consisting of 55 planning areas, one of which is the Southern Islands which are in the Central Region. Each planning area, divided into sub-zones, is envisaged to have a population of around 150,000 people (fig. 1). The Southern Islands consist of Sentosa, Tekukor, Sister Islands, Kusu and the now merged St John-Lazarus-Seringat.

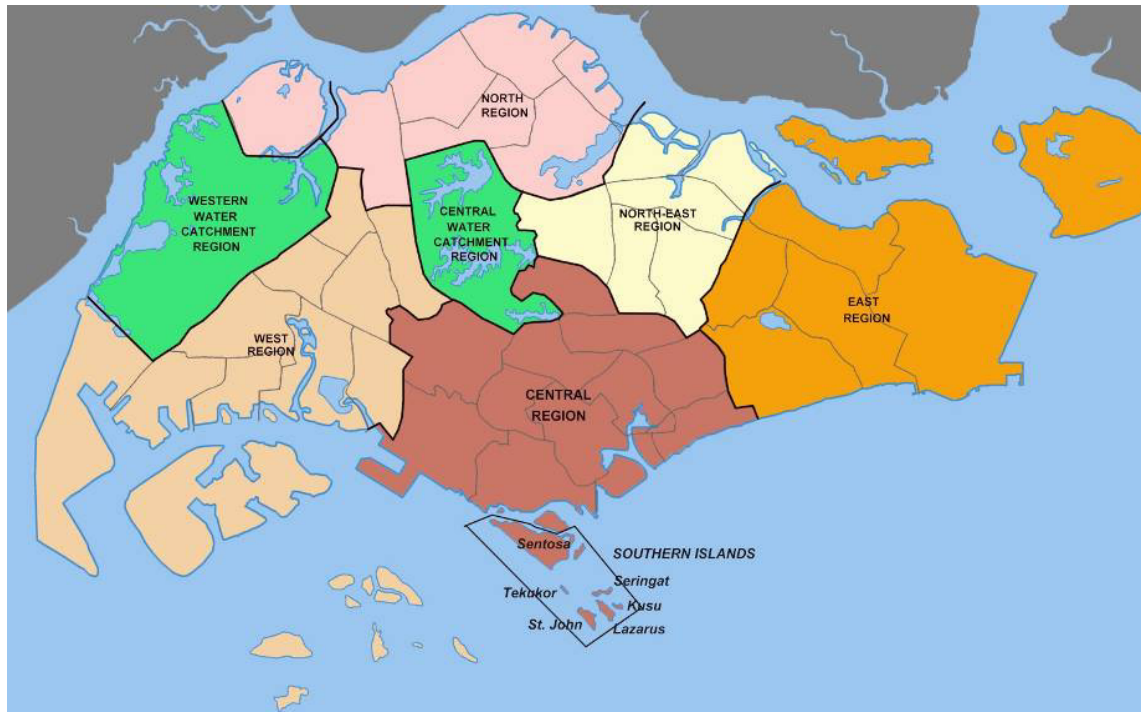

Figure 1: $\quad$ Planning regions and areas of Singapore.

In the last population census of 2000, about 3.6 million people were recorded on the $704 \mathrm{~km}^{2}$ of land on the island, giving a population density of about 5,115 people per $\mathrm{km}^{2}$. Within the Central Planning Region, the population density is higher at 6,805 people per $\mathrm{km}^{2}$. However, the Southern Islands planning area of the Central Region has a very low resident population, with some islands being uninhabited.

A mid term review of the Concept Plan in 2006 concluded that there is sufficient land in Singapore for future needs. The broad strategies arising from the revision included:

(i) A need to make more creative use of land to meet future demands;

(ii) Enhancing quality of life and sense of identity by providing a greater variety of leisure options; and to selectively retain Singapore's built and natural environment to foster a sense of belonging.

\subsection{Vision and planning strategies for the Southern Islands}

The vision for the Southern Islands is to create a tropical island destination on the doorstep of a world-class city. The planning strategies as stated in the 1996 Report included using the unique island environment for a diverse range of 
recreational activities, encouraging better utilization of the terrain and unspoilt natural areas of open space, ensuring land use compatible to the natural character of the existing environment, appreciating the island ambience by maintaining public access along the foreshore [2]. There was also a plan to provide alternative lifestyle by establishing high quality waterfront housing communities in Sentosa and Lazarus by using strategic land reclamation.

\subsection{Planning proposals of the Southern Islands}

This planning proposals covered land use, residential plan, commercial plan, green and blue plan, transportation plan, and a special and detailed control plan.

In the land use plan, of the 688.8 ha of land, $79.3 \%$ are reserved for open space and recreation, which includes beaches and parks, and open areas. The most significant proposed land use is that of residential development on reclaimed land at Sentosa Cove and Lazarus Island which accounts for $10.2 \%$ of the planning area. The introduction of residential development will provide a permanent population base. This also means that transportation will have to be upgraded or introduced so that residents can move more freely to the main island. This would pose a serious problem for Lazarus Island which is not accessible by road link compared to Sentosa which is linked to the main island by a causeway.

The proposed residential plan for Sentosa Cove has been partially implemented (fig. 2). The entire Sentosa Cove site will have a total of 2,140 units comprising 1,720 condominium units, and 420 landed units and be home to about 8,000 residents, about $60 \%$ of which are foreigners. Bungalow land parcels were first sold for $\mathrm{S} \$ 300$ psf in 2003 but climbed to $\mathrm{S} \$ 1820$ psf by 2008 . In 2009 , Seven Palms condominium started selling units at $\mathrm{S} \$ 3,300$ psf or $\mathrm{S} \$ 8.5$ million per unit. Sentosa Cove has become the most sought after address in Singapore, and this is the only area in Singapore where foreigners are allowed to own landed property. With the great success of Sentosa Cove, there is much anticipation towards the proposed development of Lazarus and whether it will be another Sentosa Cove or take on a new development concept.

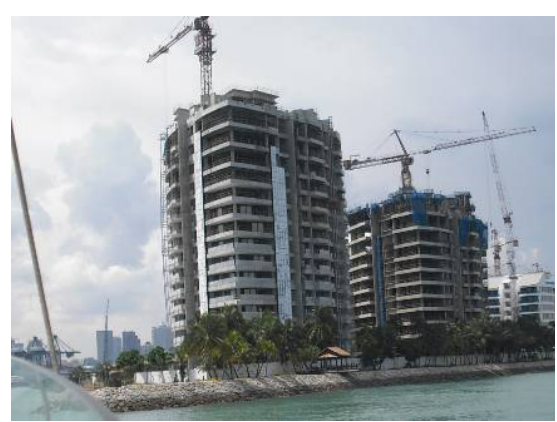

High rise condominiums

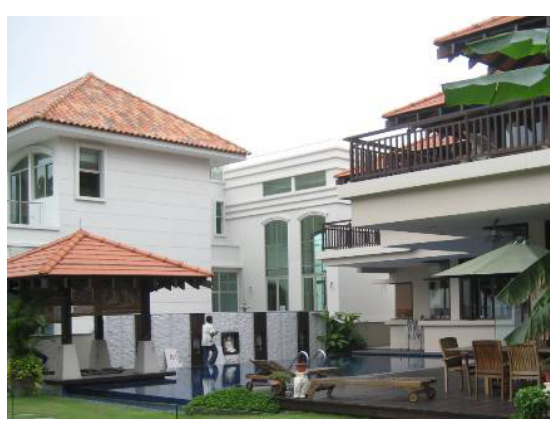

Sea-front bungalows

Figure 2: Mixed residential development on Sentosa Cove, Sentosa Island. 
In the 1996 planning report on the Southern islands, the proposed residential plan for Lazarus consisted of low density and landed housing as well as two hotels. Unlike Sentosa Cove, the proposed plan had yet to be implemented although Lazarus had been enlarged and linked to St John, and the basic utilities requirements had been put in place. Surprisingly, the 2008 Master Plan did not mention any detailed plan for developing the island.

In the Green and Blue Plan, other than the proposed commercial and residential areas, the rest of Lazarus Island is reserved for beach area, and sports $\&$ recreation. In the Special and Detailed Control Plan, the waters around Lazarus, St John and Kusu are zoned as marine nature area, and there is a restriction on development within $15 \mathrm{~m}$ of the foreshore fronting the open sea.

\section{Lazarus Island}

\subsection{History of St John-Lazarus-Kusu Islands}

Before the land reclamation of the 1960s, the area occupied by the present St John-Lazarus was a group of discrete islands dominated by St John and Lazarus, with islets of Kusu and Seringat and patchy reefs. The two larger islands, each with a school, were occupied by a decent sized population. Kusu Island was a burial site for immigrants who died in quarantine on St John and Lazarus.

As part of the Singapore Tourism Board's plan to develop the Southern Islands beyond Sentosa, a second phase of land reclamation with sands imported from Indonesia was started in 2000 to link Seringat and Lazarus and create a wide sandy bay. The new island is linked to St John by a causeway. The land reclamation took six years to complete and water, electricity, gas and telecommunication infrastructure were brought to the island from Sentosa. The entire project costs nearly $\mathrm{S} \$ 300$ million. Lazarus is accessed by passenger ferry which calls at St. John Island.

\subsection{Lazarus Island after reclamation}

Lazarus Island at the end of the reclamation is dominated by the old hill towards the south and low-lying reclaimed land to the north targeted for residential and commercial development (fig. 3). The coastline at the edge of reclaimed land is protected by high seawalls and a short causeway and bridge connect the main Lazarus Island to two small artificial islands. A longer causeway connects Lazarus to St John. To provide for recreation, a lagoon with narrow beaches has been created along the northern coast and a broad swimming bay with wide beaches backed by a sand terrace has been created along the eastern coast. Small beaches have also developed along the west coast near the main causeway and shoreline retreat behind the southern breakwaters has resulted in narrow beaches along the southern coast. One of the breakwaters formerly attached to Lazarus has become detached. The old narrow beaches below the bluff opposite Kusu island still remains. It is obviously that Lazarus is vulnerable to wave intrusion from the east, with waves approaching into the unprotected bay.

Some of the natural and man-made coasts of Lazarus are shown in fig. 4. 


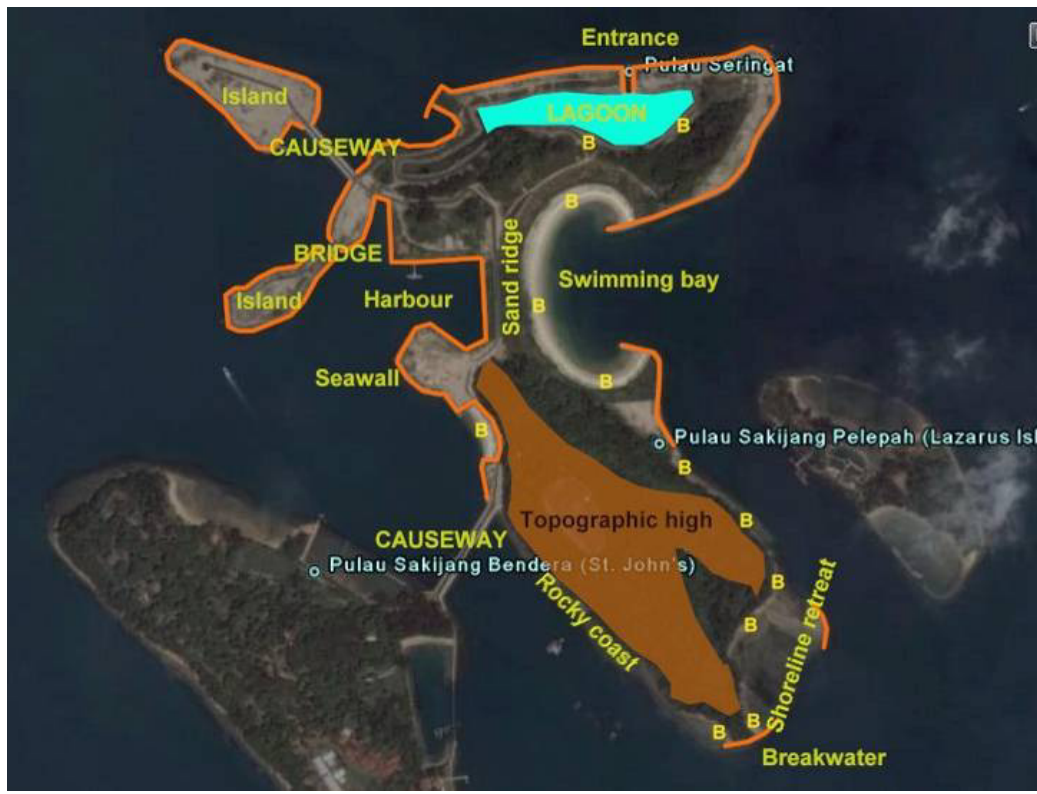

Figure 3: Lazarus Island at the end of reclamation.

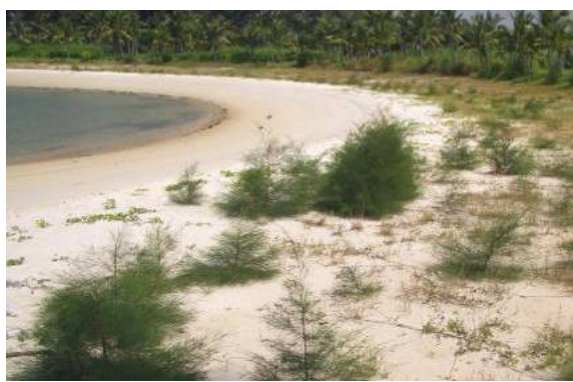

Arcuate artificial beach

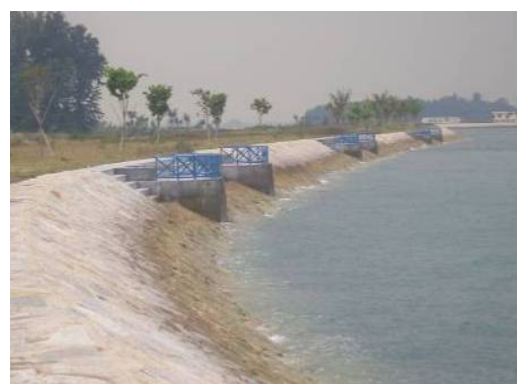

High sloping sea walls

Figure 4: $\quad$ Artificial coast of Lazarus.

\section{Sea level rise implications on Lazarus}

Only the SRES scenarios of A2 (high) for different time frames (2020, 2030, 2050 and 2100) were used to assess inundation of future sea level rise on Lazarus Island. SRES refers to the scenarios described in the IPCC Special Report on Emissions Scenarios [3]. The SRES scenarios are grouped into four scenario families (A1, A2, B1 and B2) that explore alternative development pathways, covering a wide range of demographic, economic and technological driving forces and resulting GHG emissions. The A1 storyline assumes a world 
of very rapid economic growth, a global population that peaks in mid-century and rapid introduction of new and more efficient technologies. A1 is divided into three groups that describe alternative directions of technological change: fossil intensive (A1FI), non-fossil energy resources (A1T) and a balance across all sources (A1B). B1 describes a convergent world, with the same global population as $\mathrm{A} 1$, but with more rapid changes in economic structures toward a service and information economy. B2 describes a world with intermediate population and economic growth, emphasizing local solutions to economic, social, and environmental sustainability. A2 describes a very heterogeneous world with high population growth, slow economic development and slow technological change. No likelihood has been attached to any of the SRES scenarios.

Under the A2 emission scenario, the projected global mean sea level rise by IPCC at the end of the $21^{\text {st }}$ century varies from 23 to $51 \mathrm{~cm}$ [4]. For the Lazarus study, the projected sea level rise of the regional sea for different time frames is used to establish inundation levels. These levels are higher than the IPCC projected levels. The projected sea levels, shown in table 1, follow that of Tkalich and Gulev [5]. This assumes a contribution of $20 \mathrm{~cm}$ by ice melt in 100 years and an unchanged highest astronomical tide of $1.7 \mathrm{~m}$.

Table 1: $\quad$ Projected sea level of regional seas for 2020, 2030, 2050 and 2100.

\begin{tabular}{|c|c|c|c|c|c|c|}
\hline $\begin{array}{c}\text { Time } \\
\text { scale }\end{array}$ & $\begin{array}{c}\text { Regional } \\
\text { msl } \\
\text { projection }\end{array}$ & $\begin{array}{c}\text { Ice } \\
\text { melt } \\
(\mathrm{m})\end{array}$ & $\begin{array}{c}\text { HAT } \\
(\mathrm{m})\end{array}$ & $\begin{array}{c}\text { Inundation } \\
\text { level }(\mathrm{m})\end{array}$ & $\begin{array}{c}\text { Storm } \\
\text { surge }\end{array}$ & $\begin{array}{c}\text { Extreme sea level } \\
\text { with storm surge } \\
\text { (A2 extreme) }\end{array}$ \\
\hline 2020 & 0.27 & 0.04 & 1.70 & 2.01 & 1.0 & 3.01 \\
\hline 2030 & 0.30 & 0.06 & 1.70 & 2.06 & 1.0 & 3.06 \\
\hline 2050 & 0.38 & 0.10 & 1.70 & 2.18 & 1.0 & 3.18 \\
\hline 2100 & 0.65 & 0.20 & 1.70 & 2.55 & 1.0 & 3.55 \\
\hline
\end{tabular}

In order to assess extent of inundation, a DEM of the island was created by collecting a network of elevation point data using different survey techniques, as described by Santosh et al [6]. This data set was supplemented by digital elevation information provided by Sentosa Development Corporation (SDC).

\subsection{Collecting elevation data in the field}

Over several day-visits to the island in March and April 2008 to collect elevation data, we did the following:

1. Set up a baseline consisting of two temporary bench marks (TBMs) using Trimble-R8 Real Time Kinematic (RTK) GPS.

2. Collected a network of elevation data using Nikon Total Station DTM-332 and two prisms-we selected points randomly or where changes in slope occurred.

3. Collected elevation data using mobile mapping with the RTK mounted on a truck. 


\subsection{Generating Digital Elevation Model (DEM)}

The elevation data collected was combined with data provided by SDC in a Microstation CAD platform (fig. 5). We imported the merged dataset in ArcGIS as elevation layer and then using the 3-D analyst tools in ArcGIS, generated a Triangulated Irregular Network (TIN). We further processed the TIN in ArcGIS to generate a DEM for Lazarus.

The DEM is imported into 3-D modelling software (Global Mapper) and processed to generate a $3-\mathrm{D}$ perspective view and contour map (fig. 6).

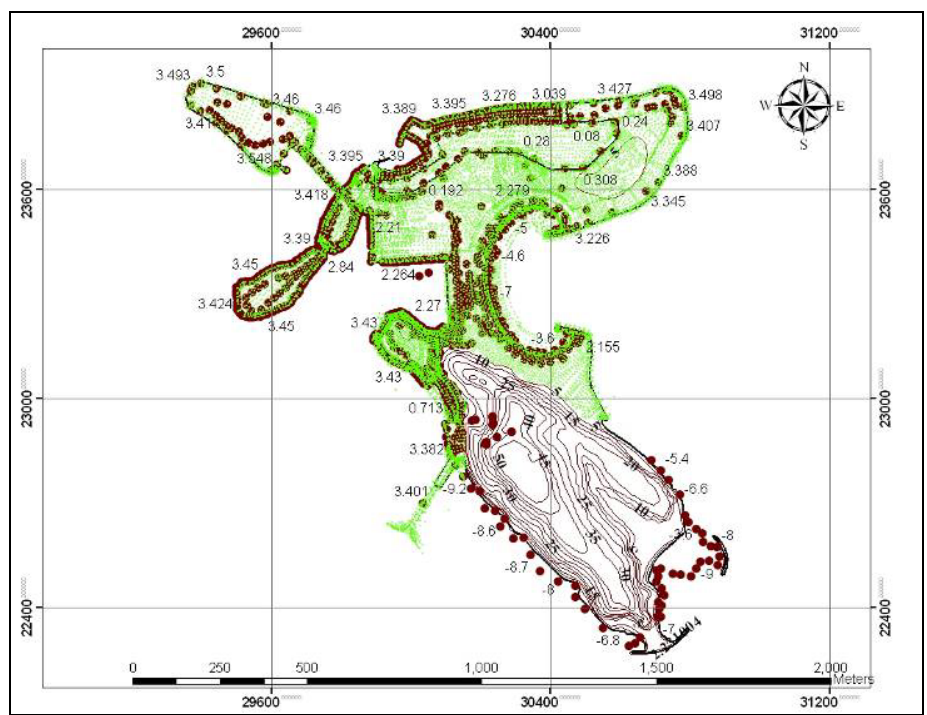

Figure 5: Lazarus: combined point and line elevation data

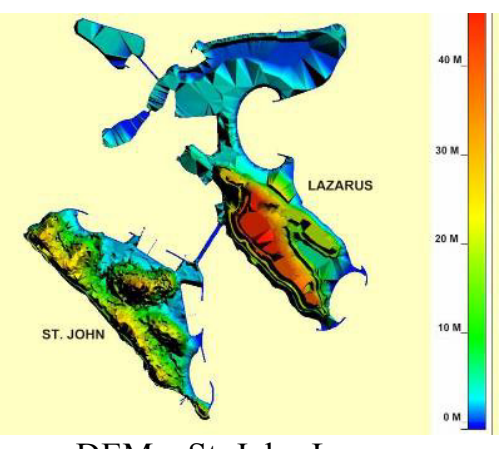

DEM - St. John-Lazarus

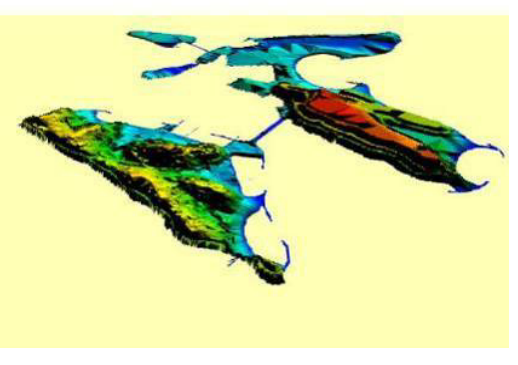

3-D perspective view

Figure 6: DEM and 3-D perspective view. 
The 3-D view toolbar in Global Mapper further allows inundation modelling for various tidal and sea level rise scenarios. The output is taken into ArcGIS for inundation area calculation.

\subsection{Present sea level and areas inundated during HAT and during HAT with storm surge of $1 \mathrm{~m}$}

To calculate the areas inundated and lost under various scenarios of sea level rise, a GIS analysis was carried out to calculate the total area of the island (75.1096 ha) and areas inundated from the coastline to highest astronomical tide (HAT) and additional areas inundated above HAT during a $1 \mathrm{~m}$ storm surge. For calculating land loss caused by a rising sea, the area above the legally defined coastline of $0.863 \mathrm{~m}$ reduced level is considered land.

The result shows that during HAT, a total area of 3.089 ha will be inundated and an additional area of 5.669 ha inundated during HAT with a storm surge of 1 m. Hence storm surge during HAT would inundate a total land area of 8.758 ha (table 2) or $11.66 \%$ of the island. The major threat of inundation comes from storm surge coinciding with HAT. A rising sea will increase this threat.

Table 2: Inundation statistics of Lazarus during HAT and HAT plus $1 \mathrm{~m}$ storm surge under present sea level.

\begin{tabular}{|c|c|c|c|}
\hline Tide level & Upper limit & Area inundated & Hectare inundated \\
\hline $0-0.863 \mathrm{~m}$ & coastline & $\begin{array}{c}\text { Upper inter tidal, beach face, } \\
\text { sea area }\end{array}$ & 2.866 \\
\hline $0.863 \mathrm{~m}$ to $1.7 \mathrm{~m}$ & HAT & $\begin{array}{c}\text { Upper beach face, berm and } \\
\text { lower scarp, land area }\end{array}$ & 3.089 \\
\hline 1.7 to $2.7 \mathrm{~m}$ & $\begin{array}{c}\text { Storm surge of } 1 \mathrm{~m} \\
\text { during HAT }\end{array}$ & $\begin{array}{c}\text { Berm, scarp and frontal } \\
\text { dune/sand terrace, land area }\end{array}$ & 5.669 \\
\hline 0.863 to $2.7 \mathrm{~m}$ & Same as above & From coastline to $2.7 \mathrm{~m}$ & 8.758 \\
\hline
\end{tabular}

\subsection{Sea level rise implications of $\mathrm{A} 2$ and $\mathrm{A} 2$ extreme emission scenarios}

Two scenarios were examined, one under A2 and the other under A2 combined with a storm surge of $1 \mathrm{~m}$. A 100-year storm surge event of $1 \mathrm{~m}$ is applied for all time frames as this event may happen in any year.

\subsubsection{A2 scenario}

The inundation statistics for A2 scenario is shown in table 3. In the absence of storm surge, inundation for all time frames can be considered minor. For example, even for the year 2100 , only 4.212 ha or $5.607 \%$ of the island will be inundated during HAT. In addition, most of the inundation will be temporary, lasting for only a few hours, with the wave overwash quickly draining away as the tide recedes. Area inundated includes the unprotected bay the proposed residential and commercial areas protected by high sea walls are not affected.

The pattern and slight spread of inundation for various time frames are shown in fig. 7. Inundation is mainly confined to the unprotected bay and the eroding southern coast. 
Table 3: A2-inundation levels and inundated areas of various time scales.

\begin{tabular}{|c|c|c|c|}
\hline Time Scale & Inundation Level (m) & Land inundated ${ }^{1}$ in ha & $\%$ land inundated \\
\hline 2020 & 2.01 & 1.444 & 1.922 \\
\hline 2030 & 2.06 & 1.665 & 2.217 \\
\hline 2050 & 2.18 & 2.426 & 3.23 \\
\hline 2100 & 2.55 & 4.212 & 5.607 \\
\hline
\end{tabular}

${ }^{1}$ permanent and temporary loss

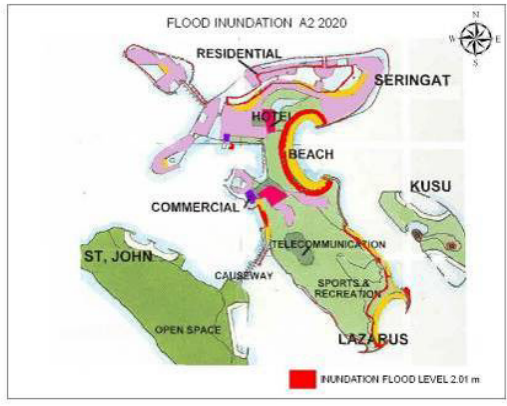

Lazarus 2020

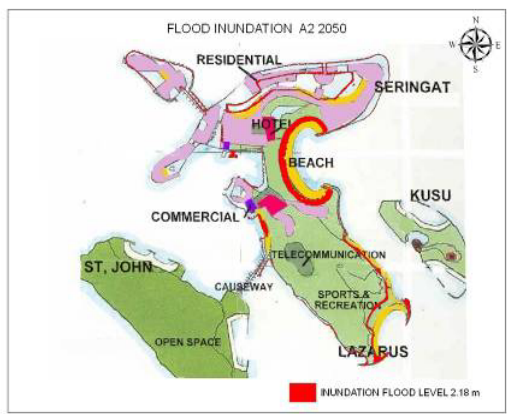

Lazarus 2050

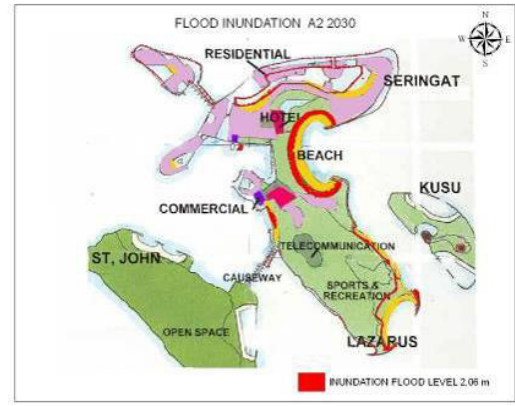

Lazarus 2030

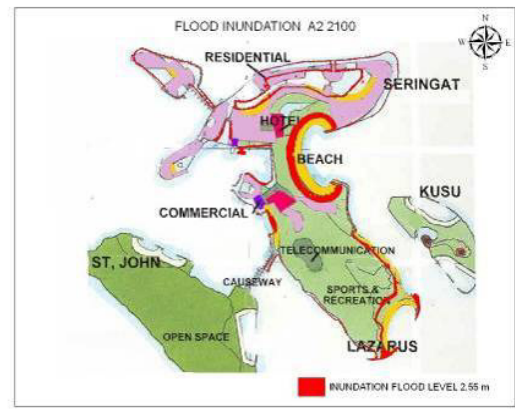

Lazarus 2100

Figure 7: A2: areas inundated during HAT for various time scales.

\subsubsection{A2 scenario (extreme)}

The inundation statistics for A2 (extreme) are shown in table 4. Combined with a $1 \mathrm{~m}$ storm surge during HAT, inundation, especially for the longer time frames, is severe and widespread. By 2020 an inundation level of $3.01 \mathrm{~m}$ will flood 9.76 ha and by 2030 an inundation level of $3.06 \mathrm{~m}$ will flood 12.6 ha of land. Areas of land flooded will increase to 21.749 ha by 2050 and to 42.144 ha or $56.11 \%$ of land by the end of the century. Inundation is mainly temporary, with wave overwash draining away as high tide recedes and storm surge abates.

The extent and spread of inundation with increasing time frames are illustrated in fig. 8. By 2020, there will be minor flooding on depressions of reclaimed land. 
Table 4: A2 (extreme)-inundation levels and inundated areas for different time scales.

\begin{tabular}{|c|c|c|c|}
\hline Time Scale & Inundation Level (m) & Land inundated in ha & \% land inundated \\
\hline 2020 & 3.01 & 9.76 & 12.994 \\
\hline 2030 & 3.06 & 12.598 & 16.773 \\
\hline 2050 & 3.18 & 21.749 & 28.956 \\
\hline 2100 & 3.55 & 42.144 & 56.11 \\
\hline
\end{tabular}

${ }^{1}$ permanent and temporary loss

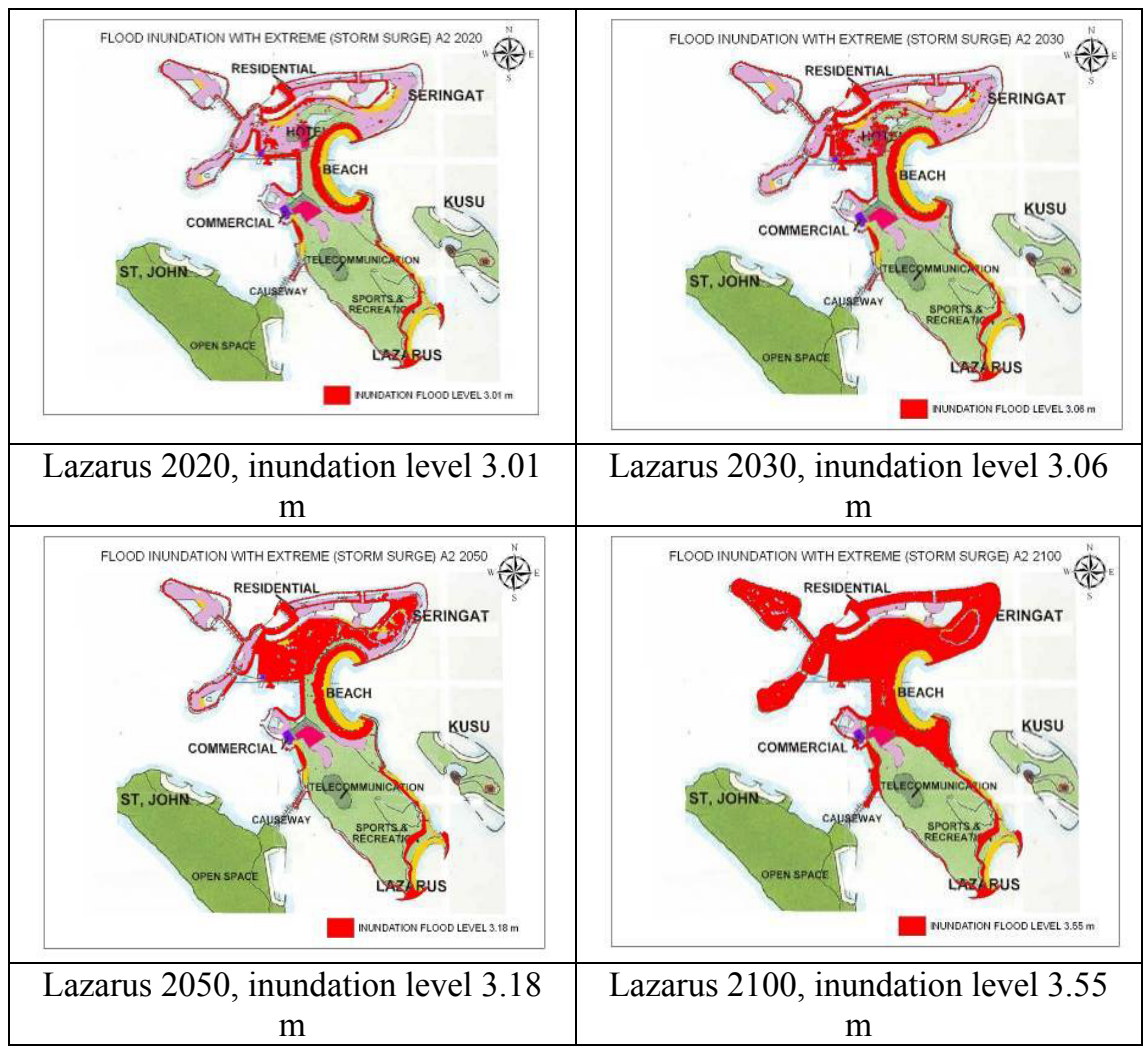

Figure 8: A2 (extreme): areas inundated for various time frames during HAT plus storm surge of $1 \mathrm{~m}$.

On the proposed residential areas, flooding becomes more pronounced by 2030 and widespread by 2050, during which the linked islets and northern coast are still inundation-free. This suggests that waves enter the lagoon to flood the land through the unprotected landward side of the lagoon coast. The sea wall and sand ridge still protects the coast from flooding at $3.18 \mathrm{~m}$ inundation level. By 
the end of the century, the sea wall set at about $3.4 \mathrm{~m}$ will be overtopped when the inundation level reaches $3.55 \mathrm{~m}$. Waves overtopping the sea wall will virtually inundate all the reclaimed areas, including the linked islets.

\section{Discussion and conclusion}

Reclaimed land along the coast or on islands is sensitive to a rising sea and storm surges. Properly-designed sea walls and a high platform level on reclaimed land will help to protect the land from erosion, wave overtopping and inundation. In land-starved Singapore, coastal land reclamation is seen as the favoured option to create land for living and development space, and land is reclaimed under stringent conditions to ensure sustainability. Fortunately, the stringent conditions are strictly adhered to as only selected government agencies can reclaim coastal land. In response to concerns about a rising sea, sea wall heights and platform levels have recently been raised in Singapore. For example the platform level for reclaimed land is now $3.0 \mathrm{~m}$ for the north coast and $3.5 \mathrm{~m}$ for the south coast.

Despite these efforts by policy makers, there is always the nagging question whether a rapidly warming world may render current standards inadequate. Once platform levels are set and buildings constructed, it will be very difficult to raise the ground level.

There is always risk in turning small islands expanded by land reclamation into expensive residential properties. People that choose to live in exclusive and small, isolated islands must bear the bulk of the risks. Small islands are more fragile and do not enjoy the resilience of most mainland ecosystems. Here nature allows little room for error. Hence, understanding island processes, vulnerabilities and choosing proper implementing strategies for sustainable development become critical for island development [7].

Similar to other low-lying small islands, Lazarus is highly vulnerable to extreme events. Although a future rising sea up to the end of the $21^{\text {st }}$ century does not pose a problem to the well protected island, a storm surge of $1 \mathrm{~m}$ coinciding with HAT will overtop the seawalls and inundate most of the reclaimed land.

For Lazarus Island to be sustainable, developers must address future sea level rise by ensuring that sea walls and platform levels are above inundation, building designs can accommodate the occasional inundation and infrastructures, especially the drainage system can collect and quickly drain away the overwash, and lastly dwellers must accept the risks that come with living beside the sea. There must also be an early warning system of extreme storm events and emergency plans for evacuation to the hill at the southern end of the island.

\section{Acknowledgements}

The help of Sentosa Development Corporation, Singapore in providing elevation data on Lazarus Island and that of Tropical Marine Science Institute, National University of Singapore in providing field assistance is gratefully acknowledged. 


\section{References}

[1] Urban Redevelopment Authority (URA), Singapore, Singapore Master Plan 2008. URA: Singapore, 2008.

[2] Urban Redevelopment Authority (URA) Singapore, Southern Islands Planning Area. URA: Singapore, 1996

[3] Nakicenovic, N. \& R. Stewart (Eds), Special Report on Emission Scenarios. A Special Report of Working Group III of the Intergovernmental Panel on Climate Change. Cambridge University Press, Cambridge: United Kingdom and New York, NY, USA, pp. 599, 2000

[4] Pachauri, R.K. \& Reisinger, A. (Eds.) Climate Change, 2007. Synthesis Report. IPCC: Geneva, Switzerland, pp. 104, 2007.

[5] Tkalich, P. \& Gulev, S., Vol. III-Coastal Hydrodynamic Studies, Singapore Climate Change, progress report 2009.

[6] Santosh, K., Raju D.K., Chandrasekhar, J. \& Teh, T.S., Field-based data collection techniques and remote sensing for developing a high resolution digital elevation model for coastal studies. Proc. of the $5^{\text {th }}$ Int. Conf. on Asian and Pacific Coasts, Vol. II, pp. 304-312, 2009.

[7] Teh, T.S., Sustainable development and environmental management of Malaysian islands (Chapter 18). Islands of Malaysia: Issues and Challenges, ed. T.S. Teh, R\&D 0237: Kuala Lumpur, pp. 319-340, 2000. 